\title{
Effects of dexmedetomidine on stress hormones in patients undergoing cardiac valve replacement: a randomized controlled trial
}

Hanhua Wu ${ }^{1+}$, Jinqing Tang ${ }^{2 \dagger}$, Jiamei Pan ${ }^{1}$, Ming Han ${ }^{1}$, Huijun Cai ${ }^{1}$ and Hong Zhang ${ }^{1 *}$

\begin{abstract}
Background: Stress response always occurs in cardiac valve replacement patients undergoing cardiopulmonary bypass (CPB).

Methods: 60 patients undergoing cardiac valve replacement were recruited and randomized into control and Dex groups. Dex group received $1.0 \mu \mathrm{g} \cdot \mathrm{kg}-1$ of Dex for $10 \mathrm{~min}$ intravenously before anesthesia, followed by $0.5 \mathrm{\mu g} \cdot \mathrm{kg}$ 1.h-1 of Dex, steadily administered throughout the procedure. And controlled group received the identical velocity of saline as Dex group. Plasma level of cortisol (Cor), epinephrine (E), norepinephrine (NE), and serotonin (5-HT) were evaluated at four timepoints: Before administration (T0), sawn sternum (T1), end of extracorporeal circulation (T2), and $24 \mathrm{~h}$ post operation (T3). General data of operation and recovery such as heart rate (HR), mean arterial pressure (MAP), intraoperative bispectral index (BIS), and hospitalization time in the intensive care unit (ICU) were also compared.

Results: Increase of Cor, E, NE, and 5-HT for the Dex group was significant lesser than that in the control group $(P<0.05)$, and ICU hospitalization time and ventilator support time was significantly shorter in the Dex group. The proportion of patients discharged from the hospital with better prognosis was significantly higher than that in the control group, while there were no significant differences in hospitalization costs and vasoactive drugs use between the two groups.
\end{abstract}

Conclusions: Dex reduces plasma Cor, E and NE elevations in patients after CPB, alleviates the stress reaction of the body, shortens the hospitalization time and ventilator support time in ICU, and plays a positive role in the rehabilitation of patients undergoing cardiac valve replacement.

Trial registration: China Clinical Trial Registry (No. ChiCTR-IPR-17010954) March 22rd, 2017.

Keywords: Dexmedetomidine, Cardiopulmonary bypass, Hormones

\footnotetext{
* Correspondence: zhzmcc@sina.com

Hanhua Wu and Jinqing Tang are Co-first author

'Department of Anesthesiology, Affiliated Hospital of Zunyi Medical

University, No. 149 Dalian Road, Huichuan District, Zunyi 563003, Guizhou

Province, China

Full list of author information is available at the end of the article
}

(c) The Author(s). 2020 Open Access This article is licensed under a Creative Commons Attribution 4.0 International License, which permits use, sharing, adaptation, distribution and reproduction in any medium or format, as long as you give appropriate credit to the original author(s) and the source, provide a link to the Creative Commons licence, and indicate if changes were made. The images or other third party material in this article are included in the article's Creative Commons licence, unless indicated otherwise in a credit line to the material. If material is not included in the article's Creative Commons licence and your intended use is not permitted by statutory regulation or exceeds the permitted use, you will need to obtain permission directly from the copyright holder. To view a copy of this licence, visit http://creativecommons.org/licenses/by/4.0/. The Creative Commons Public Domain Dedication waiver (http://creativecommons.org/publicdomain/zero/1.0/) applies to the data made available in this article, unless otherwise stated in a credit line to the data. 


\section{Background}

Cardiopulmonary bypass (CPB) immensely facilitated open heart surgical procedures such as cardiac valve replacement, benefitting patients for decades [1]. However, procedural exposure to a non-physiological condition, elicited a strong neuroendocrine stress response in patients due to several reasons such as cardiac arrest, blood dilution, and ischemia-reperfusion injury [2]. Generally, the serum hormones have a physiological circadian rhythm, with a peak in the morning between 8 and 9 a.m. Surgical stress response may be a major causative factor leading to physiological and biochemical disturbance of the homeostatic axes, primarily affecting the hypothalamic-pituitary-adrenal cortex (HPA) and locus coeruleus-sympathetic-adrenal medullary system [3]. Previously, changes in secretion of HPA related hormones such as corticotropin releasing hormone $(\mathrm{CRH})$, adrenocorticotropic hormone (ACTH), glucocorticoid (GC) and Cortisol (Cor) were observed [4]. Similarly changes in the locus system related hormones such as noradrenaline (NE), epinephrine (E) and dopamine (DA) were observed $[5,6]$.

Increased secretion of surgical stress response associated hormones could cause tachycardia and elevate myocardial oxygen demand, peripheral vascular resistance, and oxygen consumption. Moreover, $\alpha$-receptor activated sympathetic nerve stimulation may also lead to contraction of the coronary artery inducing myocardial ischemia [7]. Clinically, administration of anesthetic drugs to alleviate stress, could be effective in decreasing postoperative complications and mortality [8]. Dexmedetomidine hydrochloride (Dex) is a highly specific and selective $\alpha 2$ adrenergic receptor agonist ( $\alpha 2$-AR), having the following physiological effects: sedation, analgesia, inhibition of sympathetic nerve, alleviation of inflammatory response, and reduction of stress response [9]. Moreover, Dex was effective for blunting the elevation in systolic blood pressure and stabilizing heart rate perioperatively. And it had little adverse effect [10].

We aimed to investigate if Dex can alleviate intraoperative stress response and accelerate patient recovery by observing its effects on Cor, E, NE, and 5-HT concentration in plasma of patients undergoing cardiac valve replacement.

\section{Methods}

\section{Study design}

This was a randomized controlled clinical trial to evaluate effects of Dex administration in order to control intraoperative stress response, by observing changes in hormone levels at different timepoints. The trial adheres to CONSORT guidelines and was approved by the Ethics Committee of the First Affiliated Hospital of Zunyi
Medical University and registered in the China Clinical Trial Registry (Registration No. ChiCTR-IPR-17010954).

\section{Participants}

We selected patients who underwent cardiac valve replacement between 9:00 and 11:00 am, from March 2016 to April 2017, in the First Affiliated Hospital of Zunyi Medical University.

Inclusion criteria: (1) Age, 40-65 years; (2) American Society of Anesthesiologists (ASA) physical status classification of II or III; (3) expected operative time less than $5 \mathrm{~h}$; (4) altitude of permanent residence less than 2500 $\mathrm{m}$; (5) absence of symptoms of rheumatic fever $(\mathrm{RF}<$ 20).

Exclusion criteria: (1) Patients who discontinued anticoagulants for less than 3 days before operation; (2) Second cardiac surgery, (3) Hypertension (systolic blood pressure $\geq 180 \mathrm{mmHg}$ or diastolic blood pressure $\geq 110$ $\mathrm{mmHg}$ ), anemia (hemoglobin less than $7.0 \mathrm{~g} / \mathrm{L}$ ), low blood volume or low protein $(<30 \mathrm{~g} / \mathrm{L})$; (4) Sinus node dysfunction with impaired conduction of impulses; (5) Severe liver dysfunction (AST > 120 U/L or ALT>129 U/ $\mathrm{L})$, kidney dysfunction (SCR $\geq 150 \mu \mathrm{mol} / \mathrm{L}$ ) and coagulation disorders (INR $<1.8$ or INR $>2.0$ for aortic valve replacement patients, INR $<2.0$ or INR $>2.5$ for mitral valve replacement patients, INR $<2.5$ or INR $>3.0$ for tricuspid valve replacement patients); (6) Severe pulmonary infections and diseases (imaging results of pulmonary inflammation or respiratory symptoms such as coughing); (7) Heparin resistance and allergy in patients.

Termination criteria: (1) Uncontrollable procedural emergencies; (2) If the patient's condition was serious and they could not be successfully rescued during or 24 h after surgery; (3) Re-cardiopulmonary bypass or surgery; (4) Difficulty in cardiac resuscitation (defibrillation $>4$ beats) and cardiopulmonary bypass stopping; (5) Surgical procedures that could develop sever stress response such as intraaortic balloon pump, extracorporeal membrane oxygenation (ECMO), and deep hypothermic circulatory arrest.

The flow-diagram of participant selection is summarized in Fig. 1. Data of 60 patients were analyzed in this study.

\section{Procedures and assessments}

Participants received detailed information about this study and provided informed consent before baseline assessment, following which, study assistants opened a prepared sealed envelope containing group allocation information. Participants were randomly allocated to either a Dex group (0.2 mg Dex extracted to $50 \mathrm{~mL}$ normal saline) or control group (50 mL normal saline). In the Dex group (Group D), $1.0 \mu \mathrm{g} \cdot \mathrm{kg}^{-1}$ Dex was infused intravenously for $10 \mathrm{~min}$ before inducing 


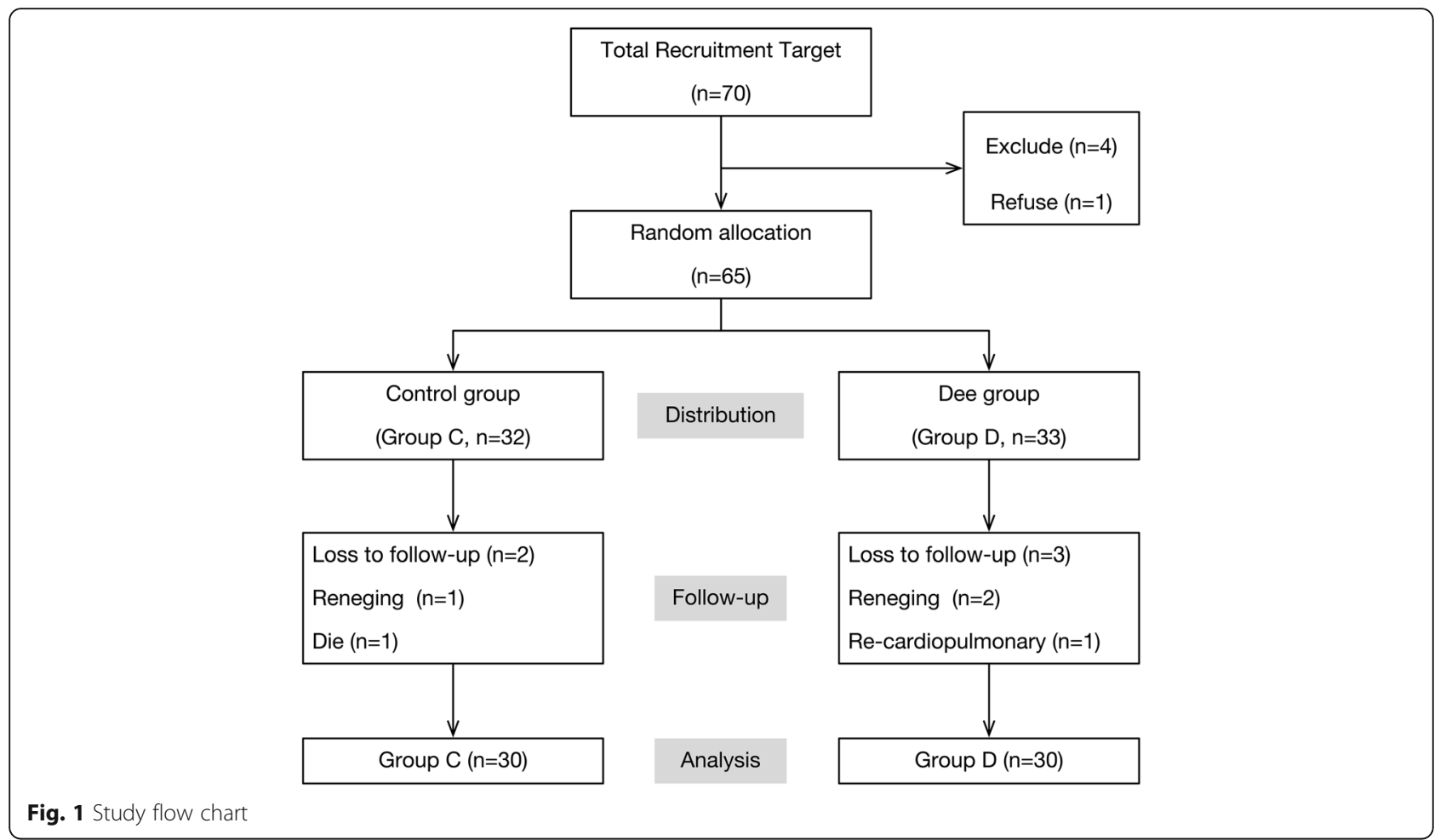

anesthesia. Subsequently, $0.5 \mu \mathrm{g} \cdot \mathrm{kg}^{-1} \cdot \mathrm{h}^{-1}$ Dex was administered for maintenance until the end of operation. Participants in the control group (Group C) were administered saline at an infusion velocity identical to that of the Dex group, in the induction and maintenance phase of the procedure.

Demographic features such as gender, age, weight, ASA level and Euroscore were collected before the surgery. During the operation, the CPB transit time, ascending aorta occlusion time, operative time and condition of cardiac resuscitation (automatic cardiac resuscitation or cardiac resuscitation after defibrillation) were recorded. Moreover, four timepoints were chosen for testing the heart rate (HR), mean arterial pressure (MAP), bispectral index (BIS) and concentration of hormones in the blood as follows: before administration (T0), at sternum sawing (T1), at end of extracorporeal circulation (T2) and $24 \mathrm{~h}$ after operation (T3). Five milliliters of blood sample of each patients were tested for the level of Cor, E, NE and 5-HT. After the surgery, the hospitalization time in ICU, ventilator support time, condition of improvement and hospitalization expense were recorded and compared between two groups. The different vasoactive drugs use (during the operation and after the operation) was also recorded and compared between two groups of patients. Patients with improvement were defined as improvement of cardiac function, no abnormity of valve replacement, normal coagulation function and general condition. The primary outcome of this study were the plasma Cor, E, NE and 5-HT level at T3, while the concentration at other timepoints were considered as secondary outcomes. In addition, the secondary outcomes included HR, MAP and BIS at all follow-ups, the ICU hospitalization time, ventilator support time, proportion of patients with improvement and discharged from hospital, hospitalization costs and the intraoperative and postoperative vasoactive drug dosage.

\section{Laboratory analysis}

Cor in plasma was measured using an enzyme-linked immunosorbent assay (ELISA) kit (Shanghai Jianglai Biotechnology Co., Ltd. Shanghai). We evaluated E, NE, and 5-HT in plasma by High Performance Liquid Chromatography (HPLC) Using Agilent 1200 high performance liquid chromatography (Agilent Company, USA). The purity of E, NE, and 5-HT standard products was higher than 99\%, purchased from Sigma Chemical Reagent Company. E was recovered by $100-117 \%$. NE and 5 -HT were successfully recovered by $100-110 \%$, respectively, and relative standard deviation of less than $5 \%$. The normal range for Cor was $20-250 \mathrm{ng} / \mathrm{mL}$. Normal ranges were $0.30-3.00 \mathrm{pg} / \mu \mathrm{L}$ for $\mathrm{E}, 0.36-1.98 \mathrm{pg} / \mu \mathrm{L}$ for $\mathrm{NE}$ and $0.97-2.09 \mathrm{pg} / \mu \mathrm{L}$ for $5-\mathrm{HT}$.

\section{Anesthesia induction and cardiopulmonary bypass management}

Anesthesia induction was achieved with midazolam $\left(0.06-0.1 \mathrm{mg} \cdot \mathrm{kg}^{-1}\right)$, sufentanil $\left(1-3 \mu \mathrm{g} \cdot \mathrm{kg}^{-1}\right)$, etomidate 
fat emulsion (0.15-0.3 $\left.\mathrm{mg} \cdot \mathrm{kg}^{-1}\right)$, and rocuronium (1 $\left.\mathrm{mg} \cdot \mathrm{kg}^{-1}\right)$. Continuous propofol $\left(4-12 \mathrm{mg} \cdot \mathrm{kg}^{-1} \cdot \mathrm{h}^{-1}\right)$ and sufentanil $\left(1-2 \mu \mathrm{g} \cdot \mathrm{kg}^{-1} \cdot \mathrm{h}^{-1}\right)$ infusions were administered intraoperatively to maintain anesthesia and muscle relaxation, and inhalational anesthetics such as sevoflurane were also used in certain situation. To ensure the safety of our patients, we kept the hemodynamics and BIS in a safe range. In order to maintain effective visceral perfusion, the MAP was controlled between 50 and 80 $\mathrm{mmHg}$, and the HR was maintained between 60 and $120 \mathrm{bpm}$. The BIS was maintained over 45 during anesthesia induction. Then the BIS was maintained between 40 and 60 during the surgery. Moreover, we also administered routine adjuvant drugs such as omeprazole, ulinastatin, and tranexamic acid.

Here, we used the cardiopulmonary bypass machine (C5, Sorin; Munich, Germany), hollow fiber super filter $\left(0.8 \mathrm{~m}^{2}\right.$, MicroPort, Dongguan, China), CPB pipeline (adult, TPRI; Tianjin, China), BIS monitoring module monitor (BeneViewT5, Mandary; Shenzhen, China) and membrane oxygenator (541,Medtronic, Memphis, United States). Crystal and colloid liquid ratio of CPB pre-filling fluid was approximately 1:1. Hematocrit (Hct) was maintained between 21 and 25\%, and suspended red blood cells were administered as required. Pre-filling fluid volume was approximately $1700-2000 \mathrm{~mL}$, and cardiopulmonary bypass was conducted during low body temperature and medium-high flow. After routine disinfection and laying the towel, skin incision, thoracotomy, $3 \mathrm{mg} \cdot \mathrm{kg}^{-1}$ heparinization, and pericardiectomy were carried out through a median incision. CPB was established by connecting the superior and inferior vena cava and ascending aorta with the corresponding pipelines of the pre-filled artificial cardiopulmonary machine. We used a perfusion needle to fix the aortic root, followed by connecting a myocardial protective fluid perfusion device. We commenced $\mathrm{CPB}$ after activated prothrombin time (ACT) of $>480 \mathrm{~s}$. During $\mathrm{CPB}$, we maintained the nasopharyngeal temperature at $32-34{ }^{\circ} \mathrm{C}$, Hct at $25-30 \%$, perfusion flow between 50 and $100 \mathrm{~mL} \cdot \mathrm{min}^{-1} \cdot \mathrm{kg}^{-1}$, and MAP at $50-80 \mathrm{mmHg}$. Furthermore, the ion-acid-base balance was maintained according to blood gas analysis. Both biological and artificial valves were used in this study.

\section{Statistical analysis}

For the sample size calculation, we considered a difference in $\mathrm{E}$ level of $1.0 \mathrm{pg} / \mu \mathrm{L}(\delta)$ between the group treated with Dex and saline as clinically relevant and we specified such an effect to be detected with $90 \%$ power (0.9) and a significance level alpha of 0.05 . For the population variance, our pilot study showed that in similar patients, the SD of E level was $1.3 \mathrm{pg} / \mu \mathrm{L}(\sigma)$. Then we used the formula $N=2 \times[(\alpha+\beta) \sigma / \delta]^{2}$ to calculate the sample size, and the sample size was at least $N=28$ patients in each group. The experimental data were analyzed by Statistical Package for the Social Sciences ver. 17.0 software (SPSS Inc., Chicago, IL). Measurement data were expressed by mean \pm SD. Count variables were compared by the Chi squared test. Two independent sample t-test was used for inter-group comparison, and repeated measurement data variance analysis was used for intra-group comparison. We considered $P<0.05$ as statistically significant.

\section{Results}

Initially 70 patients were recruited for the study, of which 5 were excluded (4 did not meet the criteria and 1 refused to participate). After randomized allocation, there were 32 cases in the control group and 33 cases in the Dex group. During the follow-up, 2 patients refused the test and quit halfway, 1 patient was re-operated and 1 patient expired. Finally, a total of 60 patients were included in the analysis, including 30 in Group $\mathrm{C}$ and 30 in Group D (Fig. 1).

\section{Comparison of clinical data between the two groups}

There were no significant differences in sex, age, weight, ASA category, Euroscore, CPB transit time, ascending aorta occlusion time, operative time, and cardiac resuscitation between the two groups $(P>0.05$, Table 1$)$.

\section{Comparison of HR, MAP, and BIS in the two groups}

There were no differences in BIS values at identical time points between the two groups $(P>0.05)$. MAP at T2 was lower than that at T0 in both the groups $(P<0.05)$, $\mathrm{HR}$ at T1 in the Dex group was the lowest, but within the normal clinical range. HR and MAP of both groups had no significant differences among other timepoints. At T1, HR in Group D was significantly lower than that in Group $C(P<0.05)$, with no significant change in MAP. Additionally, there were no significant differences in HR and MAP values between the two groups at other timepoints $(P>0.05$, Table 2$)$.

\section{Comparison of plasma Cor, $\mathrm{E}, \mathrm{NE}$, and 5-HT levels in the two groups}

In order to eliminate the influence of hemodilution after $\mathrm{CPB}$ on the results, Hct before СРВ bypass was used as the standard reference. The formula was: correction value $=$ measurement value " (Hct before bypass $/$ Hct at the corresponding blood collection times).

Comparing the two groups at different times: Compared with T0, Cor, E and NE levels showed an increasing trend, while Cor and NE concentration in both groups at T1, T2, and T3 increased significantly $(P<$ $0.05)$. The plasma Cor concentration at T2 and T3 in Group $\mathrm{C}$ was significantly higher than that at T1 $(P<$ 
Table 1 Comparison of clinical data between the two groups

\begin{tabular}{|c|c|c|c|c|}
\hline Clinical data & Group C $(n=30)$ & $\begin{array}{l}\text { Group D } \\
(n=30)\end{array}$ & $t\left(x^{2}\right)$ & $P$ \\
\hline Gender [M/F, n (\%)] & $19(63) / 11(37)$ & $16(55) / 14(47)$ & 0.617 & 0.432 \\
\hline Age (years) & $51 \pm 6$ & $49 \pm 4$ & 1.420 & 0.161 \\
\hline Weight (kg) & $55 \pm 9$ & $54 \pm 8$ & 0.015 & 0.988 \\
\hline ASA [II/III, n (\%)] & $5(17) / 25(83)$ & $9(30) / 21(70)$ & 1.491 & 0.222 \\
\hline Euroscore & $2.03 \pm 1.63$ & $1.80 \pm 1.58$ & 0.562 & 0.576 \\
\hline CPB transit time (min) & $115 \pm 34$ & $110.74 \pm 37$ & 0.502 & 0.618 \\
\hline Ascending aorta occlusion time (min) & $73 \pm 25$ & $74 \pm 36$ & 0.150 & 0.881 \\
\hline Operative time (min) & $247 \pm 39$ & $244 \pm 49$ & 0.261 & 0.795 \\
\hline Automatic cardiac resuscitation [YES/NO, n (\%)] & $2(7) / 28(93)$ & $3(10) / 27(90)$ & 0.218 & 0.640 \\
\hline
\end{tabular}

0.05), while there were no significant differences for the same at T1, T2, and T3 in Group D. The plasma E concentration at T3 in Group $C$ was significantly higher than that at T0 $(P<0.05)$, while there were no significant differences between the values at $\mathrm{T} 1$ and $\mathrm{T} 2$. There were no significant differences at T0, T1, T2, and T3 in group D. Plasma NE concentration at T0, T1, T2, and T3 in both groups, results showed a significantly increasing trend, while concentrations at each timepoint were significantly lower than the next timepoint $(P<0.05)$. The plasma 5-HT concentration at T2 and T3 was significantly higher than that at T0. When compared with T1, plasma 5-HT concentrations increased significantly at $\mathrm{T} 2$ and $\mathrm{T} 3(P<0.05)$.

At T0, there was no significant difference in plasma E, NE, 5-HT, and Cor for both groups $(P>0.05)$. At $\mathrm{T} 1, \mathrm{~T} 2$, and $\mathrm{T} 3$, the plasma $\mathrm{E}, \mathrm{NE}$, and Cor levels in Group D were lower than those in Group $\mathrm{C}(P<$ 0.05). At $\mathrm{T} 2$ and $\mathrm{T} 3$, the plasma $5-\mathrm{HT}$ levels in Group D were lower than those in Group $C(P<0.05$, Figs. 2, 3, 4, and 5).

\section{Postoperative follow-up}

ICU hospitalization time $(P=0.026)$ and ventilator support time $(P=0.042)$ were significantly shortened in Group D than in Group C (Table 3). Proportion of patients with improvement and discharged from hospital was significantly increased $(P=0.020)$. There were no significant differences in hospitalization costs and the intraoperative and postoperative vasoactive drug dosage between the two groups $(P>0.05$, Table 3 and Table 4).

\section{Discussion}

Our results showed plasma concentrations of Cor, E, NE, and 5-HT gradually increased with the prolongation of operation time. The plasma concentration of Cor, NE, and 5-HT at T2 was significantly higher than that at T0 and T1. Application of Dex preoperatively could significantly reduce plasma Cor, E, NE, and 5-HT concentrations than the control group, indicating that Dex could inhibit the stress response in patients undergoing valve replacement undergoing CPB. Moreover, 24-h follow-up showed that application of Dex could significantly improve ICU hospitalization time, ventilator support time, and rate of improvement and discharge, suggesting that it could be conducive to the recovery of patients who are undergoing $\mathrm{CPB}$.

In our study, there was no difference between Dex and control group in terms of hemodynamics, and it might

Table 2 Comparison of HR, MAP and BIS in the two groups ( $\bar{X} \pm \mathrm{SD}, n=30)$

\begin{tabular}{|c|c|c|c|c|c|}
\hline Index & Group & T0 & $\mathrm{T} 1$ & $\mathrm{~T} 2$ & T3 \\
\hline \multirow[t]{2}{*}{ HR (beats/min) } & Group C & $95 \pm 23$ & $98 \pm 27$ & $105 \pm 20$ & $103 \pm 16$ \\
\hline & Group D & $94 \pm 22$ & $78 \pm 14^{\mathrm{a}^{*}}$ & $108 \pm 18^{a b}$ & $106 \pm 16^{a b}$ \\
\hline \multirow[t]{2}{*}{ MAP (mmHg) } & Group C & $87 \pm 13$ & $83 \pm 12$ & $70 \pm 10^{a}$ & $78 \pm 11^{a}$ \\
\hline & Group D & $91 \pm 10$ & $80 \pm 14^{a}$ & $74 \pm 7^{a}$ & $82 \pm 9^{a c}$ \\
\hline \multirow[t]{2}{*}{ BIS } & Group C & $90.4 \pm 1.7$ & $37.9 \pm 1.8$ & $36.4 \pm 1.7$ & - \\
\hline & Group D & $90.7 \pm 1.8$ & $38.3 \pm 1.8$ & $36.2 \pm 1.7$ & - \\
\hline
\end{tabular}

T0 baseline; $T 1$ at sternum sawing; $T 2$ at shutdown; $T 324 \mathrm{~h}$ after operation

${ }^{*} P<0.05$ as compared with group $C$

${ }^{a} P<0.05$ as compared with T0

${ }^{b} P<0.05$ as compared with $\mathrm{T} 1$

${ }^{c} P<0.05$ as compared with T2 


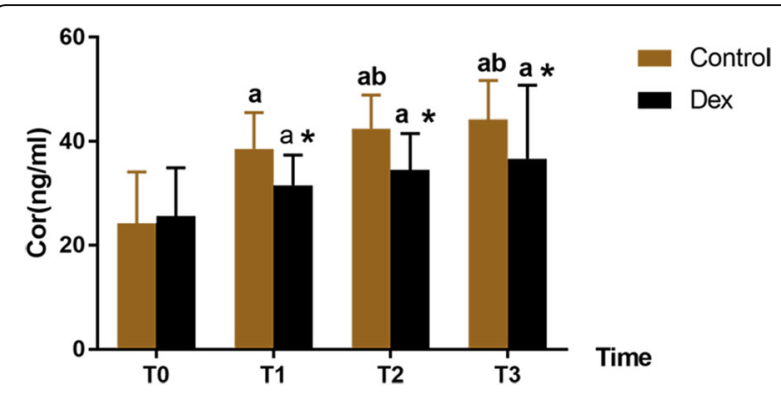

Fig. 2 Comparison of Cor concentration at different timepoints between the two groups

due to our study design. With regard to the MAP, Hashemian et al. found there was no difference between Dex and control group $0-2 \mathrm{~h}$ post $\mathrm{CPB}$, and the difference of MAP was only found 1-2 h post operation [11]. Our study was partly in accordance with their results. However, the MAP of the control group was more than $80 \mathrm{mmHg} 1-2 \mathrm{~h}$ post operation in their study, while we set our safe range of MAP between 50 and $80 \mathrm{mmHg}$. This unintentional control of HR and MAP might explain that we did not find any difference about HR and MAP between these two groups.

In healthy people, hormone secretion has a physiological circadian rhythm. For Cor, the peak of serum Cor concentration showed between 8 and 9 a.m. Then the concentration gradually decreased till 12-14 p.m. with a second peak during this period [12]. In our study, we chosen 9-11 a.m. to test the concentration of different hormones as for avoiding the impact of physiological circadian rhythm.

Recent study reported that the postoperative Cor levels did not show any difference between patients with and without $\mathrm{CPB}$, which supported that $\mathrm{CPB}$ procedure did not specifically induce the stress response compared with other surgeries [13]. During the CPB procedure, an obvious increase of Cor and catecholamines level and presence of stress response have been reported in other studies [5, 13, 14], similar to our study. Cor is a stress response biomarker and is necessary in the defense reaction of the body [15]. Moreover, it has been reported

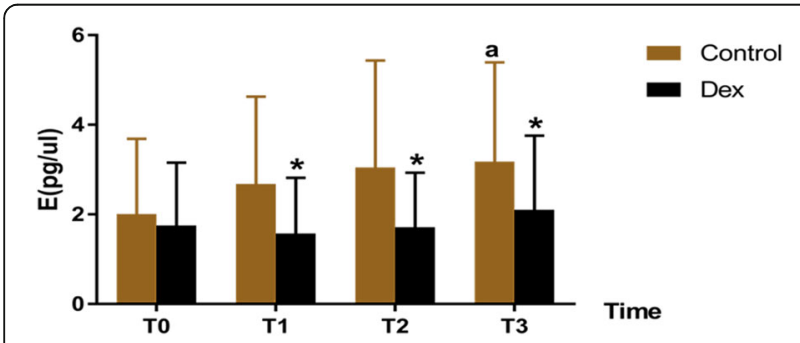

Fig. 3 Comparison of plasma E concentration at different timepoints between the two groups

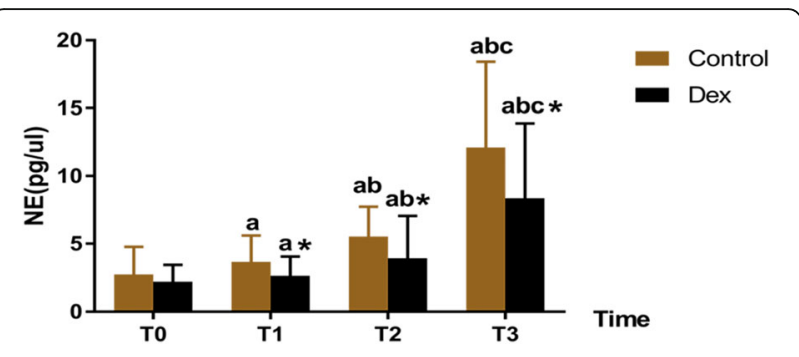

Fig. 4 Comparison of plasma NE concentration at different timepoints between the two groups

that higher Cor levels are related to longer duration of stay, longer ventilator time, higher inotrope scores, and larger fluid requirement [16]. With regard to the effect of Dex on Cor released during operation, studies showed that it could inhibit Cor secretion [17]. However, there are studies which argue about the effects of short-term Dex usage in humans. Bekker et al. reported that Dex could have a negative impact on the plasma Cor levels [18]. However, Bulow et al. did not find any differences Cor levels while using Dex in the patients undergoing mini-CPB surgery [9]. In our study, we observed that patients in Dex group had a lower plasma Cor levels. Our study used etomidate for induction, which had been reported had negative effect on Cor level till $7 \mathrm{~h}$ postinduction [19]. However, both groups of patients received etomidate for induction, and we believed the difference on Cor level between Dex and control group could reflect the effect of Dex on plasma Cor level.

Considering plasma catecholamines levels, it has been reported that $\mathrm{CPB}$ is associated with the release of catecholamines. However, our results showed a slight increase in the $\mathrm{E}$ and significant change in the NE values after $\mathrm{CPB}$, contrary to the result of a previous study, which indicated that the elevation of plasma E level was several times higher than the plasma NE level in patients after $\mathrm{CPB}$ [20]. This might be due to differences in the

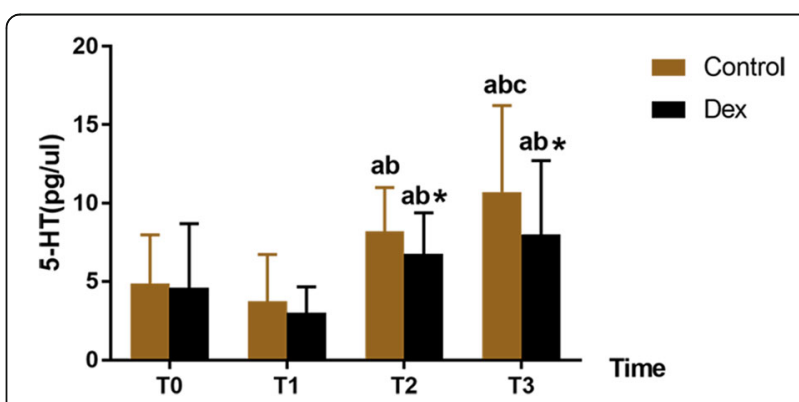

Fig. 5 Comparison of plasma 5-HT concentration at different timepoints between the two groups. Different timepoints as follows: T0: baseline; T1: at sternum sawing; T2: at end of extracorporeal circulation; T3: $24 \mathrm{~h}$ after operation 
Table 3 Comparison of postoperative follow-up between the two groups ( $\bar{X} \pm \mathrm{SD}, n=30$ )

\begin{tabular}{|c|c|c|c|c|}
\hline Postoperative follow-up & Group C & Group D & $t\left(x^{2}\right)$ & $P$ value \\
\hline Hospitalization time in ICU (h) & $90.4 \pm 72.0$ & $55.4 \pm 41.9$ & 2.30 & 0.026 \\
\hline Ventilator support time (h) & $44.5 \pm 40.20$ & $19.3 \pm 16.3$ & 2.11 & 0.042 \\
\hline Patients with improvement ${ }^{\star}$ [YES/NO, n (\%)] & $25(83) / 5(17)$ & $30(100) / 0(0)$ & 5.46 & 0.020 \\
\hline Hospitalization expenses (Ten thousand yuan) & $12.5 \pm 5.1$ & $11.4 \pm 4.4$ & 0.57 & 0.572 \\
\hline
\end{tabular}

${ }^{\triangle}$ Patients with improvement were defined as improvement of cardiac function, no abnormity of valve replacement, normal coagulation function and general condition

activation of the sympathetic nerve and adrenal medulla [21]. Plasma NE level is primarily affected by the activation of sympathetic system, which is particularly mediated by baroreceptor activation and physical issues. Additionally, hypothermia might significantly affect sympathetic nerve activation, resulting in increased plasma NE levels [20]. However, plasma E level is primarily associated with psychological stress and general and metabolic threat. Due to surgical intervention and the application of anesthetic drugs such as opioids, external nerve afferent impulse and neuroendocrine autonomic response might be blocked, resulting in an imbalances change of plasma $\mathrm{E}$ and NE levels [22].

Additionally, we observed that Dex had negatively affected both plasma E and NE levels than the control group, similar to a previous report, suggesting that the application of Dex could significantly lower the plasma Cor, E, NE, and blood glucose in pediatric cardiac surgery [23]. As the selective $\alpha 2-\mathrm{AR}$ agonist, Dex could specifically bind to presynaptic $\alpha 2-\mathrm{AR}$ and inhibit central sympathetic outflow trough a negative feedback mechanism. Due to the fact that these receptors are primarily located in the brain stem and locus coeruleus, Dex administration could significantly affect plasma NE levels [24]. Furthermore, a previous study also reported that Dex could suppress NE transporters by competitively inhibiting substrate transport [25]. With regard to the changes in the plasma E levels, it is our assumption that it might be due to the activation of both pre- and postsynaptic $\alpha$ ARs.

It has been reported that Dex could also inhibit the release of other neurotransmitters such as $\gamma$-aminobutyric acid, DA, and 5-HT in non-adrenergic neurons [26]. According to a previous animal study, 5 - HT is involved in regulation of gene expression of hypothalamic hormones and the secretion of pituitary gland hormones. The study showed that 5-HT1A receptor activation promoted acetylcholine and NE release in brain and increased the blood concentration of CRH, ACTH, and Cor [27]. Dex administration could be significantly more beneficial in treating serotonin syndrome than the current treatment involving the use of benzodiazepines in rats [28]. There is also clinical evidence demonstrating that Dex could temporally stabilize the autonomic nervous system, improve agitation, and benefit successful extubation in three cases of severe serotonin syndrome [29]. Here, we also found Dex had a negative effect on the plasma 5HT levels of patients who underwent $\mathrm{CPB}$, which might indirectly contribute to decreased Cor and catecholamine levels. Moreover, it might have a direct effect on the central 5-HT system, resulting in improved recovery after the procedure.

In our study, we found that although Dex had an elimination half-life of 2-3 h, patients received Dex treatment showed lower plasma Cor, E, NE and 5-HT level $24 \mathrm{~h}$ after the surgery. It might due to the protective effect of Dex during the surgery, which lead to relatively low level of plasma hormone after surgery. Moreover, it might reduce the stress and inflammatory response, and prevent the cardiac complications among adults undergoing surgery $[9,24]$. Chi et al. found that intraoperatively Dex use could attenuates myocardial injury in off-pump coronary artery bypass graft surgery, and it could stabilize the HR even $48 \mathrm{~h}$ after surgery [30]. In our study, we found patients in Dex group had shorter ventilator time and hospitalization time, and it might also due to the protective effect of Dex during the surgery. As an $\alpha 2$ adrenergic receptor agonist, Dex has minimal effects on respiration compared with other drugs [31]. Moreover, Dex could attenuate the lung injury and inflammation

Table 4 Comparison of dosage of vasoactive drugs used during and after the operation $(\bar{X} \pm \mathrm{SD}, \mathrm{mg})$

\begin{tabular}{|c|c|c|c|c|c|c|}
\hline \multirow[t]{2}{*}{ Vasoactive drugs } & \multicolumn{3}{|c|}{ Intraoperative dosage of vasoactive drugs (mg) } & \multicolumn{3}{|c|}{ Postoperative dosage of vasoactive drugs (mg) } \\
\hline & Group C & Group D & $P$ value & Group C & Group D & $P$ value \\
\hline Adrenaline & $0.55 \pm 0.06$ & $0.55 \pm 0.07$ & 0.798 & $0.97 \pm 0.10$ & $0.93 \pm 0.17$ & 0.272 \\
\hline Deoxyepinephrine & $0.22 \pm 0.18$ & $0.22 \pm 0.19$ & 0.891 & $0.48 \pm 0.34$ & $0.47 \pm 0.31$ & 0.910 \\
\hline Dopamine & $55.23 \pm 7.10$ & $55.00 \pm 8.59$ & 0.911 & $155.53 \pm 18.42$ & $155.44 \pm 17.52$ & 0.983 \\
\hline Glyceryl trinitrate & $5.48 \pm 0.74$ & $5.46 \pm 0.71$ & 0.958 & $5.06 \pm 0.68$ & $4.99 \pm 0.71$ & 0.730 \\
\hline
\end{tabular}


due to causes such as ischemia-reperfusion and ventilator, which might benefit respiratory function and reduce ventilator time [32, 33]. With regard to hospitalization time, study reported that intraoperative use of Dex was associated with faster recovery in patients who underwent major spinal surgery [18]. In addition, less postoperative complications might also lead to shorter hospitalization time.

There are certain limitations of our study. First, the sample size in our study is comparatively small, which might negatively influence our data. Second, we observed that a significant increase of plasma $\mathrm{E}$ level at T3, which might be correlated to the continued postoperative pumping of $E$ and stimulus of intubation, misleading the real physical values of plasma E. Third, samples could only be collected from the blood plasma, which reflects the real situation from a single perspective. Fourthly, we conducted our surgeries between 9 and 11 am. Although this period is after the peak of the plasma Cor level, the circadian rhythm of Cor could still be a factor affecting the results. Lastly, after Dex administration, there may be a significant decrease in the heart rate, which may lead to the failure of the double blinded design for this clinical trial.

\section{Conclusions}

Patients underwent CPB developed elevation of Cor, E, $\mathrm{NE}$ and 5-HT during the surgery. Dexmedetomidine can reduce Cor, E, NE, and 5-HT elevation in plasma after $\mathrm{CPB}$ in patients undergoing cardiac valve replacement, which then alleviated the stress response of the body. Moreover, it could shorten the hospitalization time and ventilator support time in the ICU, and had a positive effect on patient rehabilitation.

\section{Supplementary information}

Supplementary information accompanies this paper at https://doi.org/10. 1186/s12871-020-00993-0.

Additional file 1. Comparison of plasma Cor, E, NE and 5-HT levels in the two groups $( \pm S D, n=30)$

\footnotetext{
Abbreviations

5-HT: Serotonin; ACT: Activated prothrombin time;

ACTH: Adrenocorticotropic hormone; ASA: American Society of Anesthesiologists; BIS: Bispectral index; Cor: Cortisol; CPB: Cardiopulmonary bypass; $\mathrm{CRH}$ : Corticotropin releasing hormone; DA: Dopamine; Dex: Dexmedetomidine hydrochloride; E: Epinephrine; ECMO: Extracorporeal membrane oxygenation; ELISA: Enzyme-linked immunosorbent assay; GC: Glucocorticoid; Hct: Hematocrit; HPA: Hypothalamic-pituitary-adrenal cortex; HPLC: High Performance Liquid Chromatography; HR: Heart rate; ICU: Intensive care unit; MAP: Mean arterial pressure; NE: Norepinephrine; a2AR: $a 2$ adrenergic receptor agonist
}

Consent for publish

Not applicable.

\section{Authors' contributions}

HHW and JQT developed the concept and drafted the manuscript; JMP and $\mathrm{MH}$ performed the experiments and data acquisition; $\mathrm{HJC}$ contributed to the literature research and data analysis; $\mathrm{HZ}$ revised the manuscript. All have read the final version of this paper and have agreed with this submission.

\section{Funding}

The data acquisition, data analysis and manuscript writing of this work was funded by Guizhou Provincial Science and Technology Department [grant number SY [2015]3050] and the Project of Anesthesiology Graduate Workstation in Guizhou Province [grant number GZZ [2016]05].

\section{Availability of data and materials}

All data generated or analysed during this study are included in this published article and supplementary material 1.docx.

\section{Ethics approval and consent to participate}

The trial adheres to CONSORT guidelines and was approved by the Ethics Committee of the First Affiliated Hospital of Zunyi Medical University and registered in the China Clinical Trial Registry (Registration No. ChiCTR-IPR-

17010954). Written informed consent was obtained from each participant.

\section{Competing interests}

The authors declare that they have no competing interests.

\section{Author details}

'Department of Anesthesiology, Affiliated Hospital of Zunyi Medical University, No. 149 Dalian Road, Huichuan District, Zunyi 563003, Guizhou Province, China. ${ }^{2}$ Department of Anesthesiology, Third Affiliated Hospital of Zunyi Medical University, Zunyi 563003, Guizhou Province, China.

Received: 18 November 2019 Accepted: 27 March 2020

Published online: 06 June 2020

\section{References}

1. Featherstone PJ, Ball CM. The origins of cardiopulmonary bypass. Anaesth Intensive Care. 2018;46(4):351-3.

2. Zakkar M, Guida G, Suleiman MS, Angelini GD. Cardiopulmonary bypass and oxidative stress. Oxidative Med Cell Longev. 2015;2015:189863.

3. Mauricio Del Rio J, Nicoara A, Swaminathan M. Neuroendocrine stress response: implications for cardiac surgery-associated acute kidney injury. Rom J Anaesth Intensive Care. 2017;24(1):57-63.

4. Gajarski RJ, Stefanelli CB, Graziano JN, Kaciroti N, Charpie JR, Vazquez D. Adrenocortical response in infants undergoing cardiac surgery with cardiopulmonary bypass and circulatory arrest. Pediatr Crit Care Med. 2010; 11(1):44-51.

5. Winterhalter M, Brandl K, Rahe-Meyer N, Osthaus A, Hecker H, Hagl C, Adams HA, Piepenbrock S. Endocrine stress response and inflammatory activation during CABG surgery. A randomized trial comparing remifentanil infusion to intermittent fentanyl. Eur J Anaesthesiol. 2008;25(4):326-35.

6. Tan CK, Glisson SN, El-Etr AA, Ramakrishnaiah KB. Levels of circulating norepinephrine and epinephrine before, during, and after cardiopulmonary bypass in man. J Thorac Cardiovasc Surg. 1976;71(6):928-31.

7. Onk D, Akarsu Ayazoglu T, Onk OA, Aksut M, Gunay M, Turkmen K, Ozensoy A, Yazici Ersoy C, Coban A. Comparison of TIVA and Desflurane added to a Subanaesthetic dose of Propofol in patients undergoing coronary artery bypass surgery: evaluation of Haemodynamic and stress hormone changes. Biomed Res Int. 2016;2016:3272530.

8. Wijeysundera DN, Naik JS, Beattie WS. Alpha-2 adrenergic agonists to prevent perioperative cardiovascular complications: a meta-analysis. Am J Med. 2003;114(9):742-52

9. Bulow NM, Colpo E, Pereira RP, Correa EF, Waczuk EP, Duarte MF, Rocha JB. Dexmedetomidine decreases the inflammatory response to myocardial surgery under mini-cardiopulmonary bypass. Braz J Med Biol Res. 2016;49(4): e4646.

10. Wang XW, Cao JB, Lv BS, Mi WD, Wang ZQ, Zhang C, Wang HL, Xu Z. Effect of perioperative dexmedetomidine on the endocrine modulators of stress response: a meta-analysis. Clin Exp Pharmacol Physiol. 2015;42(8):828-36. 
11. Hashemian M, Ahmadinejad M, Mohajerani SA, Mirkheshti A. Impact of dexmedetomidine on hemodynamic changes during and after coronary artery bypass grafting. Ann Card Anaesth. 2017;20(2):152-7.

12. Debono M, Ghobadi C, Rostami-Hodjegan A, Huatan H, Campbell MJ, Newell-Price J, Darzy K, Merke DP, Arlt W, Ross RJ. Modified-release hydrocortisone to provide circadian cortisol profiles. J Clin Endocrinol Metab. 2009;94(5):1548-54.

13. Glumac S, Kardum G, Karanovic N. A prospective cohort evaluation of the cortisol response to cardiac surgery with occurrence of early postoperative cognitive decline. Med Sci Monit. 2018;24:977-86.

14. Bangalore H, Checchia PA, Ocampo EC, Heinle JS, Minard CG, Shekerdemian LS. Cortisol response in children after second cardiopulmonary bypass. Pediatr Cardiol. 2019;40(1):47-52.

15. Hoda MR, El-Achkar H, Schmitz E, Scheffold T, Vetter HO, De Simone R. Systemic stress hormone response in patients undergoing open heart surgery with or without cardiopulmonary bypass. Ann Thorac Surg. 2006; 82(6):2179-86

16. Wald EL, Preze E, Eickhoff JC, Backer CL. The effect of cardiopulmonary bypass on the hypothalamic-pituitary-adrenal axis in children. Pediatr Crit Care Med. 2011;12(2):190-6.

17. Maze M, Virtanen R, Daunt D, Banks SJ, Stover EP, Feldman D. Effects of dexmedetomidine, a novel imidazole sedative-anesthetic agent, on adrenal steroidogenesis: in vivo and in vitro studies. Anesth Analg. 1991;73(2):204-8.

18. Bekker A, Haile M, Kline R, Didehvar S, Babu R, Martiniuk F, Urban M. The effect of intraoperative infusion of dexmedetomidine on the quality of recovery after major spinal surgery. J Neurosurg Anesthesiol. 2013;25(1):16-24.

19. Hohl CM, Kelly-Smith CH, Yeung TC, Sweet DD, Doyle-Waters MM, Schulzer $M$. The effect of a bolus dose of etomidate on cortisol levels, mortality, and health services utilization: a systematic review. Ann Emerg Med. 2010;56(2): 105-13 e105.

20. Corr L, Grounds RM, Brown MJ, Whitwam JG. Plasma catecholamine changes during cardiopulmonary bypass: a randomised double blind comparison of trimetaphan camsylate and sodium nitroprusside. Br Heart J. 1986;56(1):89-93.

21. Zamparelli R, De Paulis S, Martinelli L, Rossi M, Scapigliati A, Sciarra M, Meo F, Schiavello R. Pulsatile normothermic cardiopulmonary bypass and plasma catecholamine levels. Perfusion. 2000;15(3):217-23.

22. Okuyama K, Wada K, Sakurada S, Mizoguchi H, Komatsu H, Sora I, Tamura G, Ohkawara Y, Takayanagi M, Ohno I. The involvement of micro-opioid receptors in the central nervous system in the worsening of allergic airway inflammation by psychological stress in mice. Int Arch Allergy Immunol. 2010;152(4):342-52.

23. Mukhtar AM, Obayah EM, Hassona AM. The use of dexmedetomidine in pediatric cardiac surgery. Anesth Analg. 2006;103(1):52-6.

24. Duncan D, Sankar A, Beattie WS, Wijeysundera DN. Alpha-2 adrenergic agonists for the prevention of cardiac complications among adults undergoing surgery. Cochrane Database Syst Rev. 2018;3:CD004126.

25. Park JW, Chung HW, Lee EJ, Jung KH, Paik JY, Lee KH. alpha2-adrenergic agonists including xylazine and dexmedetomidine inhibit norepinephrine transporter function in SK-N-SH cells. Neurosci Lett. 2013;541:184-9.

26. Kiski D, Malec E, Schmidt C. Use of dexmedetomidine in pediatric cardiac anesthesia. Curr Opin Anaesthesiol. 2019;32(3):334-42.

27. Jorgensen HS. Studies on the neuroendocrine role of serotonin. Dan Med Bull. 2007;54(4):266-88.

28. Kawano T, Takahashi T, Kaminaga S, Kadono T, Yamanaka D, Iwata H, Equchi S, Yokoyama M. A comparison of midazolam and dexmedetomidine for the recovery of serotonin syndrome in rats. J Anesth. 2015;29(4):631-4.

29. Rushton WF, Charlton NP. Dexmedetomidine in the treatment of serotonin syndrome. Ann Pharmacother. 2014;48(12):1651-4.

30. Chi X, Liao M, Chen X, Zhao Y, Yang L, Luo A, Yang H. Dexmedetomidine attenuates myocardial injury in off-pump coronary artery bypass graft surgery. J Cardiothorac Vasc Anesth. 2016;30(1):44-50.

31. Kim MH, Lee KY, Bae SJ, Jo M, Cho JS. Intraoperative dexmedetomidine attenuates stress responses in patients undergoing major spine surgery. Minerva Anestesiol. 2019;85(5):468-77

32. Yang CL, Tsai PS, Huang CJ. Effects of dexmedetomidine on regulating pulmonary inflammation in a rat model of ventilator-induced lung injury. Acta Anaesthesiol Taiwanica. 2008;46(4):151-9.

33. Zhang W, Zhang JQ, Meng FM, Xue FS. Dexmedetomidine protects against lung ischemia-reperfusion injury by the PI3K/Akt/HIF-1alpha signaling pathway. J Anesth. 2016;30(5):826-33.

\section{Publisher's Note}

Springer Nature remains neutral with regard to jurisdictional claims in published maps and institutional affiliations.
Ready to submit your research? Choose BMC and benefit from:

- fast, convenient online submission

- thorough peer review by experienced researchers in your field

- rapid publication on acceptance

- support for research data, including large and complex data types

- gold Open Access which fosters wider collaboration and increased citations

- maximum visibility for your research: over $100 \mathrm{M}$ website views per year

At BMC, research is always in progress.

Learn more biomedcentral.com/submissions 